\title{
The Influence of Social Media Sites on Consumer Buying Behavior in Shoprite Nigeria Limited
}

\author{
Mulikat Abdulraheem ${ }^{1 *}$; Ebun Omoniyi Imouokhome ${ }^{2}$ \\ ${ }^{1,2}$ Department of Marketing, Faculty of Management Sciences, University of Ilorin \\ Ilorin, Nigeria \\ 1'mailmulik@gmail.com; 20molebun@yahoo.co.uk
}

Received: $22^{\text {nd }}$ June 2020/ Revised: $24^{\text {th }}$ November 2020/ Accepted: $19^{\text {th }}$ January 2021

How to Cite: Abdulraheem, M., \& Imouokhome, E. O. (2021). The Influence of Social Media Sites on Consumer Buying Behavior in Shoprite Nigeria Limited. Binus Business Review, 12(2), 113-120. https://doi.org/10.21512/bbr.v12i2.6513

\begin{abstract}
Business organizations are continually searching for new ways to reach out to their consumers. Before, television, radio, and print are usually used by businesses to advertise their products. The coming of social media has shifted the way organizations interacting with their targeted audience. It has made social media an important tool for maintaining and creating a competitive advantage. Businesses today embrace the use of social media without paying adequate attention to silent issues concerning the usage of sites that can influence consumer buying behavior. The research aimed to examine the influence of social media sites on consumer buying behavior in Shoprite Nigeria Limited. The examined social media sites included Twitter, Facebook, Google+, blogs, and YouTube. The research was a descriptive design. The population was made up of consumers of Shoprite Nigeria Limited in Ibadan and Lagos. The sample size was 384 using Cochran's 1977 sample size formula for the infinite population. However, only 321 respondents filled and returned the questionnaires. A structured questionnaire was designed using a five-point Likert scale of agreement. Then, a hypothesis was tested using multiple regression analysis. The result shows that the null hypothesis is rejected. It implies that social media sites influence consumer buying behavior in Shoprite Nigeria Limited. It concludes that social media sites are important tools that can influence consumer buying behavior. It is recommended that the organization should invest more in social media sites to get in touch with their targeted audience.
\end{abstract}

Keywords: media sites, Twitter, Facebook, Google+, blogs, YouTube, consumer buying behavior

\section{INTRODUCTION}

The relevance of communication to human survival cannot be overemphasized. Apart from the basic requirements of food and shelter, human beings need to communicate with one another. The need for communication in contemporary society is a necessity to survive the ever-increasing challenges of life. Therefore, without communication, no society can exist to develop and survive. Using effective communication means is crucial to every individual or organization that has tangible things to offer. Individuals or organizations that communicate their marketing messages through the appropriate medium are likely to be successful in their businesses because clearly communicated messages avoid misunderstanding. The information that people get determines the decisions they make.

Traditional media are ways of communicating and expressing views that are before the arrival of the Internet. In the past, this media type is the only means that businesses can communicate their messages to the targeted audience. Some examples are news broadcasting and printed publications. These sets of traditional media are used in Nigeria and are identified as capable media for reaching targeted audiences. Despite the potency of these media, it is clearly on the decline. However, those are still relevant and may continue to provide value that the new medium cannot offer (Belch \& Belch, 2014).

The tools and procedures for reaching out to people have changed significantly with the development of a phenomenon known as social media. The new tool is the cheaper means of communication aiming 
at a large group of people at the same time without spending much money compared to the traditional media (Kathiravan, 2017). The evolution of social media is linked to the development of communication technology since the end of the $19^{\text {th }}$ century. It all started with Samuel Morse, who sent his first telegraph in 1844 between Washington, D.C. and Baltimore. However, communication cannot be regarded as social media because telegrams do not deal with a larger community and do not take place online. It is used to send a message between two people. Social media started in the late 1970s with the development of the Internet. It came in when most organizations searched for how they could use the computer to send messages to one another. In the 1990s, personal computers came in and set the stage for the beginning of social media. The fact that an individual could log on to the Internet, write about what he/she feels or what he/she is doing, post it to people to read, and get feedback made people understand the significance of the Internet (Jones, 2015).

Social media today has become an integral part of people's lives around the world. At the beginning of 2020 , there have been 4,5 billion users of the Internet, and about 3,8 billion are active users (Kemp, 2020). The way organizations relate with others will continue to change with social media. A new organization will be established, and individual preferences will continue to change. It is seen as the online tool that individuals use to influence the knowledge, content, points of view, and media itself. It can be referred to as social networking sites like Facebook, Twitter, Instagram, Pinterest, YouTube, and others. According to Owusu-Acheaw and Larson (2015), social media is the use of the Internet through Twitter, MySpace, Whatsapp, Facebook, and others for communicating, uploading photos and videos, and sharing of ideas by users.

Business organizations today have realized that technology is a major factor in expanding markets. It has contributed to the entire marketing strategies around the world. Advertising and sales promotion also focus on emotional, physical, and social factors compelling to consumer behavior. Hence, it is an element that must be unified into technology-based marketing (Akram \& Kumar, 2017). As a result, organizations need to consider the four essentials of the marketing mix: product, price, place, and promotion (Akram \& Kumar, 2017). The idea of social media has topped the list of many business executives, decision-makers, and consultants. They try to look for means to make use of the available applications profitably. This application includes YouTube, Facebook, Twitter, Wikipedia, and others. Consumers mostly use the Internet to check message content, watch it, read it, and use the content to buy products and services needed (Pourkhani, Abdipour, Baher, \& Moslehpour, 2019).

Social media sites are important tools that organizations cannot ignore to succeed in contemporary society. In today's competitive environment, it is not just enough for organizations to maintain a good relationship with their consumers and make a profit. However, they need to reach them on a one-to-one basis, and satisfaction should be a great concern. The strategy of targeting not only the profit aspect of an organization but also reaching the consumers in the most convenient form to build a viable and profitable relationship should be considered. Many organizations just embrace the use of social media without paying adequate attention to the salient issues concerning the usage of sites that can influence consumer buying behavior.

Several sites can affect consumer buying behavior. There are several used sites in the research. First, Twitter is a very popular platform for businesses to get in touch with their consumers. One important feature of Twitter is that users can follow other users without invitation. Twitter shows information about the company's products, the number of tweets and uploaded videos/pictures, and the number of followers. Business owners can easily set up their Twitter account and decide not to link the user account to a corporate identity. The features of Twitter have great benefits to businesses that are just introducing a new product to a targeted market. With Twitter, the organization does not need any big advertising campaigns (Jaring, Bäck, Komssi, \& Käki, 2015). It is found out that Twitter positively influences consumer behaviour.

Second, Facebook has become the most popular social media site with over 2,07 billion users monthly (Alzougool, 2018). In recent times, Facebook has become one of the most important technologies around the world. Businesses today use Facebook to reach out to their consumers. For example, Shoprite Nigeria Limited post messages to consumers regarding prices of products, availability of new products, and promotion on Facebook. It also uploads pictures of what it can offer, and consumers can make comments, ask questions, and share their thoughts. Previous studies agree that Facebook influences consumer behavior (Tzavara, Clarke, \& Misopoulos, 2019; Akpan, Nwankpa, \& Agu, 2015).

Third, Google+ is also one of the most important social media platforms. It is used by small and medium-scale businesses. It is a site that should be used by businesses (Akram \& Kumar, 2017). Business organizations use Google + to reach out to their consumers and potential consumers worldwide. However, previous researchers are yet to look at how it can influence consumer buying behavior.

Fourth, blogs are platforms for passing information, communicating, and marketing. Organizations around the world use this platform as an important part of their marketing strategy. Blogs is a social media site within the Web 2.0 platform. The platform serves as a means that various forms of content can be used differently and for different purposes (Wilson, Kenny, \& Dickson-Swift, 2015). Most businesses now use a business blog as a marketing channel that can improve business growth. Consumers see blogs as a valuable tool that helps them to gather information about a product and get inspiration for 
future purchases (Penttala \& Saarela, 2012).

Fifth, YouTube is one of the most powerful social media platforms worldwide. Marketing managers are now using video content to reach out to their targeted audience, and YouTube is a great platform to do it. YouTube has brought a change from stagnant to a dynamic social network, and its quality lies in the format of the video and the content. It allows the advertising of professional videos (Martinho, Pinto, \& Kuznetsova, 2012). Moreover, consumers search for the best products and services that can satisfy their needs, at the same time, affordable. Satisfied consumers are the driving force for brand success (Hanaysha, 2017). The business organization can better satisfy these consumers when they upload informative videos about their products and services on YouTube. The organization can as well interact with these consumers. The more opportunities to the prospects to make comments about a product or service are, the better chance the organization has in influencing the prospects. It is found out that YouTube influences consumer buying behavior. Consumers see it as a credible and trustworthy source of information (Młodkowska, 2019). Another previous research tries to find if YouTubers can influence consumer buying behavior in the retail industry. The findings show that factors such as relatability, trend, product details, and interactivity on YouTube can affect consumer buying behavior (Misra \& Mukherjee, 2019). Then, social media marketing has a significant impact on consumers' engagement and brand loyalty (Muchardie, Yudiana, \& Gunawan, 2016).

Social media sites include Facebook, Blogs, Twitter, Google+, YouTube, Linkedln, and others. The recent trends in social media sites can influence consumer behavior in all the decision-making stages (Voramontri \& Klieb, 2019). Many factors can influence consumer buying behavior. The purchases that the consumers make and the stores that they patronize are ultimately determined by the interactions of various influences of consumer buying behavior. It is the responsibility of the retail industry to find out these factors and put them in place to enable these consumers to make purchases. Moreover, marketing managers experience problems with the use of social media from how to manage consumer creation and engagement, how to manage multi-sided markets, how to adjust to the changing consumer purchase decision, and how to create a compelling and profitable interaction (Hofacker \& Belanche, 2016).

Consumer buying behavior is how buyers act, function, and respond to different circumstances involving buying goods or services or the acknowledgment. It can be seen as a summation of consumers' intentions, preferences, attitudes, and decisions concerning their attitude in the targeted marketplace where they purchase goods and services (Ramya \& Ali, 2018). It is also an integral part of strategic market planning. Every business organization must study the buying behavior of its targeted audience (Pawar \& Naranje, 2016).
A business organization cannot achieve its aims and objectives if its marketing strategies are inadequate. Consumers are always the core of every marketing planning strategy. Therefore, the success of a business organization is determined by its consumers because they generate revenue for the organization by buying and influencing others to buy (Auf, Meddour, Saoula, \& Majid, 2018). Retail organizations in Nigeria today have developed significantly. Most of them have a website that they can upload messages and pictures and interact with their consumers and potential consumers (Chinwendu \& Shedrack, 2018).

Consumer buying behavior is greatly influenced by several factors that appear to look like uncontrollable variables from marketers' point of view. These factors are so interlinked and connected. Hence, that is why consumers behave differently (Kumar, 2019). According to Kotler and Amstrong (2018), consumer buying behavior is strongly influenced by social, psychological, personal, and cultural factors. In psychological characteristics, an individual's buying decision can be influenced by four psychological characteristics: motivation, learning, perception and beliefs, and attitudes. Then, for personal characteristics, an individual's decision can also be influenced by the buyer's occupation, self-concept and personality, age, and life-cycle stage. Marketers are expected to monitor these factors to provide goods and services that will best suit these factors. Next, in cultural characteristics, marketers must understand the role played by the buyer's culture, subculture, and social class. Marketers must understand those factors because buyers with a similar culture, subculture, and social class tend to exhibit buying behavior.

Social exchange theory is propounded by Emerson (1976). The theory involves using moneysaving advantage structure and evaluations of the similarities of alternatives to explain how people communicate with each other, how they build relationships, and how communities are built as a result of exchanging. The theory expresses that people take part in practices that they find fulfilling and dodge practices with too high cost. The theory is relevant to the study because social media has to communicate with one another and build relationships through various platforms. Individuals and organizations make use of it because it is cheaper compared to traditional communication media. This theory can also be linked to the definition of social media by Owusu-Acheaw and Larson (2015). They viewed social media as the use of the Internet through Twitter, MySpace, WhatsApp, Facebook, and others to communicate, upload photos and videos, and share ideas with users.

Relevant theories to social media indicate that it is an essential tool for an organization that wants to stand the test of time. Therefore, it is an important independent variable to consumer buying behavior. Some previous studies are related to consumer buying behavior. First, Sharma and Bhatt (2018) investigated the impact of social media on consumer buying behavior. A descriptive study was conducted using 
Technology Acceptance Model (TAM). The objective was to examine the relationship between perceived value, perceived risk, and perceived usefulness and see how these three factors influenced purchase intention. The sample size was 265 students undergoing postgraduate programs, and the collected data were analyzed using correlation and regression analysis. The findings show that there was a significant correlation among the three factors. All factors had a positive effect on purchase intention for those who made their purchase online. They concluded that organizations that sold their products online should understand the online shopping behavior of their consumers as it would help to stimulate demand.

Second, Chinwendu and Shedrack (2018) examined the influence of social class on consumers' shopping behavior in Nigeria. A survey research method was adopted, and 384 structured questionnaires were distributed out in which 350 copies were filled and used for the analysis. Chi-square and multiple regression were used to test the collected data. The research revealed that social class significantly influenced consumers' choice of shopping outlets. It concluded that consumers showed a very strong link regarding the choice of their shopping outlet.

Third, Ertemel and Ammoura (2016) examined the role of social media advertising on consumer buying behavior in the fashion retail industry in Turkey. Electronic questions were formulated, and the data were analyzed using regression analysis. The result revealed that social media advertising affected consumer buying behavior. It was concluded that the fashion retail industry should design their advertisement to support the industry and consumer buying behavior that would benefit both sides.

Fourth, Khan, Al-balushi, Algaithi, and Al-Shihi (2017) investigated the impact of social media on consumer satisfaction. The objective was to determine the challenges faced by the consumers in Bank Muscat when transacting with the bank through social media. A purposive sampling method was used to select 234 respondents. Then, simple random sampling was used to distribute the questionnaires to the respondents. The results revealed that social media had a positive influence on consumers' satisfaction. It was concluded that Bank Muscat should make use of social media for marketing purposes.

Sixth, Ogunyombo, Oyero, and Azeez (2017) studied the effect of social media advertising on purchase decisions of undergraduate students at three Nigerian universities. They examined the exposure, viewership, and influence of social media advertising on the purchase decision. A survey design was adopted, and 385 students made up the sample size. The result revealed that social media advertising was excellent in terms of exposure. However, it was limited in influencing respondents' purchase decisions. The research concluded that business organizations should create awareness through social media.

Most businesses and organizations dive into social media sites to influence consumer buying behavior and increase consumer's patronage. However, many are disappointed when it fails to achieve the desire results. Social media is important, but it is misunderstood in some ways. One of those misunderstandings is that business should be on social media sites. There are many social media channels to choose from, but deciding which ones deserve attention can be difficult. Several big supermarkets in Nigeria, including Shoprite Nigeria limited, already engage their consumers through social media sites, but the question is whether they achieve expected results or not.

Based on the mentioned description, the research seeks to see how social media sites affect consumer buying behavior and to examine the effect of social media sites on consumer buying behavior in Shoprite Nigeria Limited. The formulated null hypothesis is that social media sites do not have any significant effect on consumer buying behavior. It is expected to be tremendous assistance to the retail industry, specifically Shoprite Nigeria Limited, and know which social media sites to reach their consumers and influence their buying behavior. It will also serve as a guide to policymakers and business organizations in making sound decisions on reaching their consumers using the various social media sites.

\section{METHODS}

The research adopts a descriptive quantitative method with a survey design to enhance a proper understanding of the research variables. The population is the consumers of Shoprite Nigeria Limited in Ibadan and Lagos. We have seven Shoprite outlets in these cities, two in Ibadan and five in Lagos. The research randomly selects three outlets in Lagos and one outlet in Ibadan. Hence, four outlets are used for the research. The sample size formula for the infinite study population by Cochran (1977) is used to obtain a representative sample of 384 respondents. The formula is shown in Equation (1).

$$
n_{o}=\frac{z^{2} p q}{e^{2}}
$$

Where,

$$
\begin{aligned}
\mathrm{n}_{0}= & \text { Sample size } \\
\mathrm{z}= & \text { Value (the chosen critical value of the preferred } \\
& \text { confidence level) } \\
\mathrm{p}= & \text { Proportion (proportion of an attribute that is } \\
& \text { currently in the population) }
\end{aligned}
$$

Here is the example of calculating the sample size in which the population is large, and the degree of variability is unknown. Assuming the variability is $50 \%$ which is 0,5 and taking $95 \%$ confidence level with $\pm 5 \%$ precision, it has $p=0,5$. Hence, it is $q=1-0,5=$ 
0,$5 ; \mathrm{e}=0,05$; and $z=1,96$. Then, the calculation is as follows.

$$
n_{0}=\frac{\left(1,96^{2}\right) \times(0,5)(0,5)}{0,052}=384,16=384
$$

The respondents are selected through the convenience sampling method. The primary source of collecting data is used to elicit information from the respondents. A structured questionnaire is designed for the research. The questionnaire consists of items to measure the influence of social media on consumer buying behavior. It uses a five-point Likert scale of agreement from $(1=$ strongly agree to $5=$ strongly disagree). For positively worded items, the scoring pattern is 5 to 1 in descending order of magnitude. Meanwhile, for negatively worded items, the scoring is reversed from 1 to 5 in ascending order of magnitude.

Multiple regression techniques are used to test the formulated null hypothesis. This technique helps to point out the most significant variable among independent variables that best predict consumer buying behavior in Shoprite Nigeria Limited. Moreover, the validity and reliability test are also conducted.

\section{RESULTS AND DISCUSSIONS}

Around 384 questionnaires are administered. However, only 321 are adequately filled and used for the analysis. The research reveals that social media sites significantly affect consumer buying behavior in Shoprite Nigeria Limited. Table 1 presents Cronbach's alpha for each of the dimensions of the variables. Meanwhile, the used indicators and variables are stated in Table 2.

Table 1 Cronbach's Alpha of the Variables

\begin{tabular}{clccc}
\hline S/N & Dimensions & $\begin{array}{c}\text { Number } \\
\text { of items }\end{array}$ & $\begin{array}{c}\text { Cronbach's } \\
\text { alpha }\end{array}$ & $\begin{array}{c}\text { Internal } \\
\text { consistency }\end{array}$ \\
\hline 1. & Twitter & 7 & 0,956 & Excellent \\
2. & Facebook & 6 & 0,914 & Excellent \\
3. & Google+ & 8 & 0,955 & Excellent \\
4. & Blogs & 9 & 0,968 & Excellent \\
5. & YouTube & 7 & 0,969 & Excellent \\
6. & $\begin{array}{l}\text { Consumer } \\
\text { buying behavior }\end{array}$ & 4 & 0,717 & Acceptable \\
\hline
\end{tabular}

To test the questionnaire as a research instrument, the validity and reliability test is carried out. The content validity of the instrument is done by giving it to three experts in the Faculty of Management Sciences, University of Ilorin, Nigeria. The experts certify that the instrument has content validity, and the instrument is said to be adequate for the research. Meanwhile, the reliability test result shows that each score for Twitter, Facebook, Google+, Blogs, and YouTube is greater than 0,9 . It indicates that the variables fall into the excellent region of internal consistency.

On the other hand, scores for consumer buying behavior are greater than 0,7 but less than 0,8 . It means that it is in the acceptable region of internal consistency. It implies that there is internal consistency among the items grouped for each dimension. The results can be seen in Table 1. Hence, the instrument fulfills the criteria of validity and reliability.

Table 2 Operational Variables

\begin{tabular}{|c|c|}
\hline Variable & Indicators \\
\hline \multirow{4}{*}{ Twitter } & Twitter account \\
\hline & Tweets \\
\hline & Tweet update \\
\hline & Feedbacks \\
\hline \multirow{4}{*}{ Facebook } & Facebook account \\
\hline & Messages \\
\hline & Photos \\
\hline & Chat \\
\hline \multirow{4}{*}{ Google+ } & Google account \\
\hline & Invitation \\
\hline & Updates \\
\hline & Video chatting \\
\hline \multirow{4}{*}{ YouTube } & Subscriber \\
\hline & YouTube channel \\
\hline & Video clips \\
\hline & Embedded videos \\
\hline \multirow{3}{*}{$\mathrm{B} \log s$} & Messages \\
\hline & Updates \\
\hline & Remarks \\
\hline \multirow{5}{*}{$\begin{array}{l}\text { Consumer buying } \\
\text { behavior }\end{array}$} & Awareness \\
\hline & Reach \\
\hline & Interaction \\
\hline & Attention \\
\hline & Persuasion \\
\hline
\end{tabular}

Table 2 presents the indicators to measure the research variables. The indicators for Twitter are Twitter account, tweets, tweet updates, and feedbacks. Then, the indicators for Facebook include Facebook account, messages, photos, and chats. Meanwhile, Google + indicators are Google account, invitation, updates, and chats. Next, YouTube indicators include subscribers, YouTube channels, video clips, embedded videos. Blogs indicators are messages and updates. Last, the indicators of consumer buying behavior are awareness, reach, interaction, attention, and persuasion.

Table 3 presents the model summary of the effect of social media sites on consumer buying behavior in Shoprite Nigeria Limited. It shows that the value of 
Table 3 Model Summary ${ }^{\mathrm{b}}$

\begin{tabular}{cccccc}
\hline Model & R & R-Squared & $\begin{array}{c}\text { Adjusted } \\
\text { R-Squared }\end{array}$ & $\begin{array}{c}\text { Std. Error of the } \\
\text { Estimate }\end{array}$ & Durbin-Watson \\
\hline 1 & $0,773^{\mathrm{a}}$ & 0,597 & 0,589 & 1,092 & 1,855 \\
\hline
\end{tabular}

a. Predictors: (Constant), YouTube, Facebook, Twitter, Google+, and Blogs

b. Dependent Variable: Consumer Buying Behavior

(Source: Authors' Computation, 2020)

Table 4 The Result of Analysis of Variance (ANOVA ${ }^{a}$ )

\begin{tabular}{clccccc}
\hline & Model & Sum of Squares & Df & Mean Square & F & Sig. \\
\hline \multirow{2}{*}{1} & Regression & 274,667 & 5 & 54,933 & 95,854 & $0,000^{\mathrm{b}}$ \\
& Residual & 185,109 & 323 & 0,573 & & \\
& Total & 459,775 & 328 & & & \\
\hline
\end{tabular}

a. Dependent Variable: Consumer Buying Behavior

b. Predictors: (Constant), Youtube, Facebook, Twitter, Blogs, and Google+

(Source: Authors' Computation, 2020)

Table 5 The Result of Coefficients ${ }^{\mathrm{a}}$ of Determination

\begin{tabular}{|c|c|c|c|c|c|c|}
\hline & \multirow{2}{*}{$\begin{array}{c}\text { Model } \\
\text { B }\end{array}$} & \multicolumn{2}{|c|}{ Unstandardized Coefficients } & \multirow{2}{*}{$\begin{array}{c}\text { Standardized } \\
\text { Coefficients }\end{array}$} & \multirow{2}{*}{$\mathbf{T}$} & \multirow{2}{*}{ Sig. } \\
\hline & & Std. Error & Beta & & & \\
\hline \multirow{6}{*}{1} & (Constant) & 2,772 & 0,130 & & 21,362 & 0,000 \\
\hline & Twitter & 0,022 & 0,005 & 0,219 & 4,185 & 0,000 \\
\hline & Facebook & 0,006 & 0,002 & 0,171 & 3,233 & 0,001 \\
\hline & Google+ & 0,001 & 0,002 & 0,027 & 0,511 & 0,610 \\
\hline & Blogs & 0,007 & 0,004 & 0,090 & 1,738 & 0,083 \\
\hline & YouTube & 0,014 & 0,003 & 0,226 & 4,256 & 0,000 \\
\hline
\end{tabular}

a. Dependent Variable: Consumer Buying Behavior

(Source: Authors' Computation, 2020)

$\mathrm{R} 2$ is 0,597 . It indicates that social media sites explain about $59,7 \%$ of the variation in consumer buying behavior in Shoprite Nigeria Limited. Meanwhile, the remaining $40,3 \%$ are explained by other variables that are outside of the model. Moreover, the DurbinWatson statistic shows that the model is free from serial correlation as its value is close to 2 .

Table 4 shows the Analysis of Variance (ANOVA) of the model. It shows the F-statistic with a value of 95,854 and a probability value of 0,000 , which is less than conventional significance levels of 0,05 . It depicts that the reported F-statistic is significant. It means that the overall model is significant. In other words, social media sites significantly affect consumer buying behavior in Shoprite Nigeria Limited. Hence, the null hypothesis is rejected.

Then, Table 5 presents the coefficients of the effect of social media sites on consumer buying behavior. The result shows that social media sites, such as Twitter, Facebook, Google+, Blogs, and YouTube, influence consumer buying behavior in Shoprite Nigeria Limited. From all positive effects, Twitter, Facebook, and YouTube are found to be statistically significant at 0,05 of the conventional level of significance. It is evident from their probability values (Sig.). Those are less than 0,05. However, the effect of Google+ and blogs is not statistically significant at a conventional significance level of $5 \%$. Their probability values are greater than 0,05 . The significant positive standardized coefficient values of 
Twitter, Facebook, and YouTube $(0,219,0,171$, and 0,226 , respectively) indicate an increase in the use of each social media site by Shoprite Nigeria Limited on consumer buying behavior by $21,9 \%, 17,1 \%$, and $22,6 \%$ respectively.

Twitter is perceived as an essential site by the respondents in influencing their buying behavior. The result is in line with Read, Robertson, McQuilken, and Ferdous (2019). Shoprite Nigeria Limited has a Twitter account. The posted tweets on this account are capable of influencing consumer buying behavior. Quick response to messages on the account also encourages the consumers to buy.

Similarly, the respondents mention that Facebook is an important site that influences their buying behavior. The result is supported by the finding of Tzavara et al. (2019) and Akpan et al. (2015). Shoprite Nigeria limited is equipped with features that are useful to consumers. They upload their profile, send messages, upload pictures, and give room for chatting.

On the other hand, Google+ is seen as a site that is not essential in influencing consumer buying behavior. It can be connected to the usage of the features of this site because it requires an invitation by another Google+ user before the user can join the account. It can discourage consumers from accessing the site.

YouTube is also perceived as an important site by the respondents in influencing consumer behavior. It has a similar result with Młodkowska (2019). Shoprite Nigeria Limited uploads video clips on its YouTube account and allows those that subscribe to the channel to share the videos across the Internet through websites, mobile devices, and emails.

Next, blogs are also another site that is seen as not important in influencing consumer buying behavior by the respondents. It is contrary to the findings of Penttala and Saarela (2012). It is also connected to the usage of the features of this site. Blogs are just online journals that everyone with a web connection can gain access to.

In summary, improving the use of Twitter, Facebook, and YouTube and their features will positively impact consumer buying behavior in Shoprite Nigeria Limited. YouTube, Twitter, and Facebook are strong social media sites that Shoprite Nigeria Limited should consider. It is connected to the usage of the provided features by each site. An increase in the use of YouTube, Twitter, and Facebook will better influence consumer buying behavior.

\section{CONCLUSIONS}

The way that businesses use social media sites today has led to the belief that it is a special tool for reaching out to their targeted audiences. Organizations are continually searching for new methods that can influence consumer buying behavior. Based on the test, social media sites, such as Twitter, Facebook, and
YouTube, significantly influence consumer buying behavior. It implies that Shoprite Nigeria Limited has been achieving expected results using Twitter, Facebook, and YouTube to influence consumer buying behavior. Shoprite Nigeria Limited is known worldwide for selling goods at a lower price. It can use these platforms to post information about the availability of its products and sell those at a lower price. Then, it will influence consumer buying behavior. Also, it gives a discount on the product purchased during festive occasions. This information is communicated to consumers through these sites. However, the result shows that Google+ and blogs do not significantly influence consumer behavior. It means that Shoprite Nigeria Limited needs to re-consider these sites' features to see how they can influence consumer buying behavior. Finally, the study recommends that Shoprite Nigeria Limited to invest more in social media sites like Twitter, Facebook, and YouTube. These sites should be updated regularly to encourage consumers and potential consumers to make trial and repeat purchases. It should continue to use significant social media sites to reach out to its consumers.

The result of research will help superstores in Nigeria, especially Shoprite Nigeria Limited. However, the research is limited to the key variables in social media used by Shoprite Nigeria Limited. Hence, the result may not be generalized. Future research may focus on other social media sites that can influence consumer behavior, such as Instagram, Linkedln, WhatsApp, MySpace, and others.

\section{REFERENCES}

Akpan, C. S., Nwankpa, N. N., \& Agu, V. O. (2015). Influence of Facebook advertisement on the buying behaviour of students of a Nigerian university. International Journal of Humanities and Social Science, 5(7), 135-148.

Akram, W., \& Kumar, R. (2017). A study on positive and negative effects of social media on society. International Journal of Computer Sciences and Engineering, 5(10), 347-354.

Alzougool, B. (2018). The impact of motives for Facebook use on Facebook addiction among ordinary users in Jordan. International Journal of Social Psychiatry, 64(6), 528-535.

Auf, M. A. A., Meddour, H., Saoula, O., \& Majid, A. H. A. (2018). Consumer buying behaviour: The roles of price, motivation, perceived culture importance, and religious orientation. Journal of Business and Retail Management Research, 12(4), 177-186.

Belch, G., \& Belch, M. (2014). The role of new and traditional media in the rapidly changing marketing communications environment. International Journal of Strategic Innovative Marketing, 1(3), 130-136.

Chinwendu, O. D., \& Shedrack, M. C. (2018). Investigating the influence of social class on consumers' shopping behaviour in Nigeria. International Journal of Marketing Research Innovation, 2(2), 38-48. 
Cochran, W. G. (1977). Sampling techniques. New York: John Wiley and Sons.

Emerson, R. M. (1976). Social exchange theory. Annual Review of Sociology, 2(1), 335-362.

Ertemel, A. V., \& Ammoura, A. (2016). The role of social media advertising in consumer buying behavior. International Journal of Commerce and Finance, 2(1), 81-89.

Hanaysha, J. R. (2017). Impact of social media marketing, price promotion, and corporate social responsibility on customer satisfaction. Jindal Journal of Business Research, 6(2), 132-145.

Hofacker, C. F., \& Belanche, D. (2016). Eight social media challenges for marketing managers. Spanish Journal of Marketing-ESIC, 20(2), 73-80.

Jaring, P., Bäck, A., Komssi, M., \& Käki, J. (2015). Using Twitter in the acceleration of marketing new products and services. Journal of Innovation Management, $3(3), 35-56$.

Jones, M. (2015). The complete history of social media: A time line of the invention of online networking. Retrieved October $4^{\text {th }} 2020$ from https:// historycooperative.org/the-history-of-social-media/

Kathiravan, C. (2017). Effectiveness of advertisements in social media. Asian Academic Research Journal of Multidisciplinary, 4(7), 179-190.

Kemp, S. (2020). Digital 2020: 3.8 billion people use social media. Retrieved October $4^{\text {th }} 2020$ from wearesocial. com/blog/2020/01/digital-2020-3-8-billion-peopleuse-social-media

Khan, F. R., Al-balushi, H., Algaithi, A., \& Al-Shihi, A. (2017). Impact of social media on customers satisfaction: Bank Muscat-A case study. Ahead International Journal of Recent Research Review, 1(11), 154-163.

Kotler, P., \& Amstrong, G. (2018). Principles of marketing. Hoboken: Pearson Higher Education.

Kumar, A. (2019). Factors influencing consumer behaviour. Journal of Emerging Technologies and Innovative Research, 6(8), 757-763.

Martinho, M., Pinto, M., \& Kuznetsova, Y. (2012). Scholars' YouTube channels: Content analysis of educational videos. Internet Latent Corpus Journal, 2(2), 76-90.

Misra, P., \& Mukherjee, A. (2019). YouTuber icons: An analysis of the impact on buying behaviour of young consumers. International Journal of Business Competition and Growth, 6(4), 330-345.

Młodkowska, B. (2019). Influencers on Instagram and YouTube and their impact on consumer behaviour. Journal of Marketing and Consumer Behaviour in Emerging Markets, 8(1), 4-13.
Muchardie, B. G., Yudiana, N. H., \& Gunawan, A. (2016). Effect of social media marketing on customer engagement and its impact on brand loyalty in caring colours cosmetics, Martha Tilaar. Binus Business Review, 7(1), 83-87.

Ogunyombo, O., Oyero, O., \& Azeez, K. (2017). Influence of social media advertisements on purchase decisions of undergraduates in three Nigerian universities. Journal of Communication and Media Research, 9(2), 244-255.

Owusu-Acheaw, M., \& Larson, A. G. (2015). Use of social media and its impact on academic performance of tertiary institution students: A study of students of Koforidua Polytechnic, Ghana. Journal of Education and Practice, 6(6), 94-101.

Pawar, S., \& Naranje, S. (2016). A study on factors influencing on buying behaviour of customers. SSRN.

Penttala, S., \& Saarela, H. (2012). Study on the effect of blogs on young women's online buying behaviour when purchasing fashion items from online stores. Journal of Engineering and Management Sciences, 3(7), 15-35.

Pourkhani, A., Abdipour, K. H., Baher, B., \& Moslehpour, M. (2019). The impact of social media in business growth and performance: A scientometrics analysis. International Journal of Data and Network Science, 3(3), 223-244.

Ramya, N., \& Ali, S. M. (2018). A study on consumer buying behaviour towards Amul products with special reference to Coimbatore city. International Journal of Applied Research, 4(7), 353-357.

Read, W., Robertson, N., McQuilken, L., \& Ferdous, A. S. (2019). Consumer engagement on Twitter: Perceptions of the brand matter. European Journal of Marketing, 53(9), 1905-1933.

Sharma, B. K., \& Bhatt, V. K. (2018). Impact of social media on consumer buying behavior-A descriptive study on TAM model. i-Manager's Journal on Management, 13(1), 34-43.

Tzavara, D., Clarke, P., \& Misopoulos, F. (2019). An investigation of the impact of Facebook and Instagram on consumer buying behaviour: The case of retail fashion consumers in Rhodes, Greece. International Journal of Business \& Economic Sciences Applied Research, 12(2), 81-87.

Voramontri, D., \& Klieb, L. (2019). Impact of social media on consumer behaviour. International Journal of Information and Decision Sciences, 11(3), 209-233.

Wilson, E., Kenny, A., \& Dickson-Swift, V. (2015). Using blogs as a qualitative health research tool: A scoping review. International Journal of Qualitative Methods, 14(5), 1-12. 